\title{
Human immobilization: is the experience in Moscow just the beginning?
}

In late October 2002, several dozen Chechen terrorists commandeered and shortly thereafter controlled and secured a theatre in Moscow containing more than 800 people who were attending a play. The militants, who had several political demands, threatened to blow up the theatre and thus kill themselves and all the hostages if their requests were not met within a short time, a day or two. Apparently, Russian antiterrorist experts and police who had no visual contacts with the terrorists and no way of entering the building without the militants' knowledge made little progress with attempts to talk the terrorists out of their mission and thus had a huge dilemma with little time for alternatives. The issue boiled down to concede to the militants' demands or attempt some sort of rescue that, ideally, would harm few or none of the hostages. The latter approach was risky since some or all of the terrorists claimed to have explosives strapped to their bodies, which they threatened to detonate upon any attempt to rescue the hostages. The former approach was politically unacceptable.

The Russian President, Vladimir Putin, made a decision to rescue the hostages in spite of the huge potential for loss of life if the attempt did not succeed. It is not clear if storming the building forcefully with special forces, antiterrorist experts and/or police was a realistic option. It probably was not. In any event, a decision was made to use a chemical immobilizing agent(s). It appears from reports that the agent(s) was probably nebulized and, using a forcedair system, pumped into the air ducts that led into the auditorium. The aerosolized chemical-immobilizing agents were at first not identified, but later, after significant national and international political and media pressure, suggested to be 'fentanyl derivatives' by the Health Minister, Yuri Shevchenko. Shevchenko also said that 'one thousand antidotes' (which he would not name) were on hand at the time of the rescue.

Correspondence to: Theodore Stanley, Department of Anesthesiology, University of Utah, 30 North 1900 East, Room 3C444, Salt Lake City, UT 84132, USA. E-mail: theodore.stanley@hsc.utah.edu; Tel: +1 801581 2707; Fax: +1 801 5859267

Accepted for publication February 2003 EJA 1448
One report from a laboratory in Germany analysing some blood from two German hostages suggested that halothane might have been one of the immobilizing agents.

The rescue attempt resulted in the deaths of 128 hostages (123 from the chemical agents). Dozens of other hostages required hospitalization, some with apparently serious but not clearly defined medical problems. Virtually all the terrorists were killed, many by the chemical agents, but some were shot after being subdued by the drugs. The loud outcry and criticism of the Russian decision and rescue attempt in the international media was impressive and prolonged. Somewhat lost in the attention focused on the number of casualties in the rescue was the fact that more than 650 hostages survived, most with no obvious residual medical problem. It is interesting to note that during a news conference at the time, the US President, George W. Bush, pointed out this fact.

It appears from the numerous eyewitness reports, observations of physicians who treated the hostages, statements by Russian officials, and newspaper and magazine articles that a potent opioid was at least one of the chemical agents used. Some unidentified Moscow physicians reported that the patients had classic signs of 'opioid intoxication: pin point pupils, unconsciousness, depressed respiration and cyanosis'. One physician reported that all the hostages treated at his hospital were given naloxone, and all responded. However, at least one other physician said many of the cases were perplexing.

The Russian authorities refused specifically to identify the fentanyl derivatives used in the rescue attempt. A group of scientists and immobilization experts in the USA, including Mr Parker Ferguson (a former government chemist, who is now an independent consultant on chemical and biological terrorism), Dr James H. Woods (Professor of Pharmacology, University of Michigan), and the present author, believe the most likely fentanyl derivative used was carfentanil [1]. Although not approved by the US Food and Drug Administration for use in human beings, carfentanil is available for veterinarians for immobilization of certain wild animals. It is sold under the 
trade name of Wildnil ${ }^{\circledR}$ (Wildlife Pharmaceuticals Inc., Fort Collins, CO, USA) and is approximately 80-100 times more potent than fentanyl and eight to 10 times more potent than sufentanil [2-4]. In animal studies (undertaken at the Janssen Laboratories, Beerse, Belgium; unpublished data), carfentanil was shown to possess opioid activity and an onset of action similar to fentanyl and sufentanil with a duration only slightly longer than sufentanil. Its therapeutic index in rats was 10000 , which compared favourably with fentanyl (a therapeutic index of 400) and alfentanil (1000), but was less than sufentanil (25000). Carfentanil was never brought to the human market place because its perceived advantages over the other fentanyls (potency and therapeutic index) were not considered significant enough to justify the cost. Carfentanil's potency makes it feasible as a candidate to immobilize hundreds of people in a large auditorium. An extremely potent material such as carfentanil would best explain the rapid, effective immobilization of the occupants of the auditorium. In addition, studies in the 1980s showed that carfentanil could be easily nebulized to anaesthetize primates rapidly (P. Ferguson, unpublished data, T. H. Stanley, unpublished data). These effects were easily antagonized with naloxone.

Whether halothane, presumably in a low, subanaesthetic dose, was also a component of the immobilizing mixture is difficult to say. If it were, it would have significantly decreased the volume of carfentanil or any other opioid required. On the other hand, all therapeutic index studies ever performed with opioids and other agents, including inhaled agents, have demonstrated that many supplements dramatically reduce the therapeutic index of all opioids, making them much riskier drugs to consider for immobilization [4].

How should the medical and scientific community deal with the problem presented to the Russian President and his government last autumn and their decision to use a chemical-immobilizing agent to solve quickly and as safely as possible that problem? The author is not an expert or authority on the ethics or possible alternatives of such a choice. It is also true that currently available opioids and other possible chemical alternatives still present a significant risk if considered for human immobilization. However, remarkable progress has been made in the techniques to deliver immobilizing agents and in the development of safer, faster-acting potent compounds of extremely short duration in the last decade. Much of this work is either privileged or currently not available to the public and therefore unpublished. Some of this work will have important clinical utility when it becomes more widely known in the future.

While chemical compounds have been considered and used as weapons of war for almost a century, they have always invoked feelings of revulsion, disgust and terror. A number of different chemical poisons were used by both sides in the First World War. For more than 60 years after the War, the US government and many other Western European governments had active programmes evaluating chemical irritants, as well as compounds that could totally incapacitate and, in some circumstances, kill human beings if used in the battlefield as well as in a city or individual building. In the last 20 years, international treaties banning the use of chemical compounds as weapons of mass destruction have curtailed much active research in this area. Programmes that continued have focused on the use of chemical (and non-chemical) approaches to immobilize human beings safely and rapidly and then to reverse immobilization with 'less than lethal' techniques for domestic crowd control, hostage rescue and similar problems. The time may now have come to expand this research so that these and superior techniques and drugs may be used by special forces to deal with terrorists attempting to extort governments into politically unacceptable concessions by threatening hundreds or thousands of innocent human lives.

$$
\begin{array}{r}
\text { Theodore Stanley } \\
\text { Department of Anesthesiology } \\
\text { University of Utah } \\
\text { Salt Lake City } \\
\text { USA }
\end{array}
$$

\section{References}

1. Brown D, Baker P. Moscow gas likely a potent narcotic; drug normally used to subdue big game. Washington Post, 9 November 2002, A12.

2. Meuleman T, Williard K, Port JD, Stanley TH, Kimball J. Immobilization of elk and moose with carfentanil. $J$ Wildl Manag 1984; 48: 258-262.

3. Bailey PL, Port JD, Pace NL, Stanley TH. The $\mathrm{ED}_{50}$ of carfentanil for elk immobilization with and without the tranquilizer R51703. J Wildl Manag 1985; 49: 931-934.

4. Stanley TH, Port JD. Letter to Editor - Fentanyl 'anesthesia' in dogs. Anesthesiology 1985; 62: 837-838. 